\title{
Non-Adherence to Anti-Hypertensive Treatment
}

\section{Shalini ${ }^{1}$, Manish Kumar Goel ${ }^{2}$}

${ }^{1}$ MBBS Student, Lady Hardinge Medical College \& Associated Hospitals, New Delhi; ${ }^{2}$ Professor, Department of Community Medicine, Lady Hardinge Medical College \& Associated Hospitals, New Delhi

\begin{tabular}{|c|c|c|c|c|c|c|c|c|}
\hline Abstract & Introduction & Methodology & Results & Conclusion & References & Citation & \multicolumn{2}{|c|}{ Tables / Figures } \\
\hline \multicolumn{9}{|c|}{ Corresponding Author } \\
\hline \multicolumn{8}{|c|}{$\begin{array}{l}\text { Dr Manish Kumar Goel, Professor, Department of Community Medicine, Lady Hardinge Medical College, } \\
\text { New Delhi-110001 } \\
\text { E Mail ID: drmanishgoel2000@yahoo.co.in }\end{array}$} & 口iris \\
\hline
\end{tabular}

\section{Citation}

Shalini, Goel MK. Non-Adherence to Anti-Hypertensive Treatment. Indian J Comm Health. 2020;32(1):126-129.

Source of Funding: ICMR, New Delhi Conflict of Interest: None declared

\section{Article Cycle}

Received: 04/02/2020; Revision: 18/02/2020; Accepted:15/03/2020; Published:31/03/2020

This work is licensed under a Creative Commons Attribution 4.0 International License.

\section{Abstract}

Background: In developed countries, adherence among patients suffering from chronic diseases averages only $50 \%$; in developing countries it is assumed to be much lower. Aims \& objectives: To find out the prevalence of non-adherence to antihypertensive treatment among individuals seeking anti-hypertensive treatment from tertiary care hospital in New Delhi $\&$ to find out the factors related to non-adherence to the anti-hypertensive treatment among study subjects. Material and Methods: A cross-sectional hospital-based study was conducted from June to October 2018 among 150 diagnosed cases of hypertension. The drug adherence was assessed by using standard Brief Medication Questionnaire I (BMQ I) and to know the determinants of non-adherence a semi-structured (self-designed and pre tested) questionnaire was used. The association of different factors with adherence was analyzed by applying chi square ( $\chi 2)$ test. Results: Among total of 150 participants $44 \%$ were males and $56 \%$ were females. The magnitude of non-adherence to anti-hypertensive drugs was $35.3 \%$. Side effects of anti-hypertensive drugs was significant risk factor for non-adherence to anti-hypertensive drugs and common reasons for non-adherence were unwanted side effects (64.2\%) followed by worry about long term side effects (62.3\%). Conclusion: Prevalence of non-adherence to anti-hypertensive drugs was quite high, most common reason for non-adherence to antihypertensive medication was unwanted side effects and worry about long term side effects.

\section{Keywords}

Adherence; Anti-Hypertensive Treatment; Hypertension

\section{Introduction}

Chronic non-communicable diseases (NCDs) are posing a serious threat to public health throughout the world, irrespective of whether developed and developing. (1) NCDs are responsible for $70 \%$ of deaths worldwide (2) and $61 \%$ of deaths in India.(3)

Hypertension is one of the most significant risk factor for cardiovascular morbidity and mortality. Prevalence of hypertension is $30-32 \%$ globally,(4)and ranges from $27 \%$ to $33 \%$ in India.(5) Hypertension follows the "Rule of halves" i.e. only half of the hypertensive subjects in the general population were aware of the condition, only about half of those aware of the problem were being treated, and only half of those treated were considered adequately treated.(6) WHO defines adherence as the extent to which a person's behavior- taking medication, following a diet, and/or executing lifestyle changes, corresponds with agreed recommendations from a health care provider. $(7,8)$

In developed countries, adherence among patients suffering from chronic diseases averages only 50\%, whereas the magnitude and impact of poor adherence in developing countries is assumed to be much higher due to the paucity of health resources and inequities in access to health care. Researchers have found that half of those with "refractory" hypertension are in fact non adherent. (9) Such high levels of noncompliance are of tremendous concern, given the serious consequences of uncontrolled hypertension on cardiovascular, cerebrovascular, and renal morbidity as well as mortality. There can be many barriers to drug adherence which include poor providerpatient communication, inadequate knowledge about a drug and its use, not being convinced of the need for treatment, fear of adverse effects of the drug, long term drug regimens, complex regimens that require numerous 
medications with varying dosing schedules, pill burden, cost and access barriers. $(10,11,12,13)$ Although, a large number of studies on patient adherence have been made during the past years; we still face the problem of nonadherence. There is paucity of studies of adherence to antihypertensive treatment among patients diagnosed with hypertension, so we planned the study for the same.

\section{Aims \& Objectives}

To find out the prevalence of non-adherence to antihypertensive treatment among diagnosed hypertensive subjects attending follow up OPD at LHMC. To find out the factors related to non-adherence to the anti-hypertensive treatment among study subjects.

\section{Material \& Methods}

A cross-sectional hospital based analytical epidemiological study was conducted from June 2018 to October 2018. The study was conducted in Smt. Sucheta Kripalani Hospital, a tertiary care government hospital under Lady Hardinge Medical College; among diagnosed cases of hypertension coming to Medicine OPD for follow up during the study period. A total of 150 , pre diagnosed cases of hypertension ( $>30$ years of age, both sexes), who are on antihypertensive medication at least for period of last 6 months were included in the study. The sample size was calculated by assuming the prevalence of nonadherence as $50 \%$ (8) at $95 \%$ level of significance and $20 \%$ allowable error with a design effect of 1.5. Every consecutive pre diagnosed case of hypertension ( $>30$ years of age) presenting in the medicine OPD during the study time period enrolled in the study consecutively until the desired sample size is met. Written and informed consent was taken from all the study participants. Confidentiality of all the data was ensured by keeping the responses anonymous. Moreover, the collected data is stored under secure settings. The study was approved by the institutional ethical committee.

The drug adherence was assessed by using standard Brief Medication Questionnaire I (BMQ I) and to know the determinants of non-adherence a semi-structured (selfdesigned and pre tested) questionnaire was used. The patients who were illiterate or had difficulty in understanding the questionnaire, were assisted by an interview. BMQ I was administered to each study subject to know the drug adherence, which includes information about details of their prescribed medication regimen. Prescriptions, available at the time of the interview, were used in getting reliable data. Wherever prescriptions were not available, the medicine/drug strips used by the respondents were sought and noted. A standard drug manual was used to find out the generic class of the drug. Adherence as a percentage has been computed as (number of doses of medication taken in the last week /number of doses of medication prescribed for that week) $x$ 100. This adherence value is treated as a continuous variable and associations were tested based on categories of $\geq 80 \%$ adherence. ( 8 )

All data collected were entered into Excel spreadsheets of Microsoft Office 2003. Qualitative data were analyzed using proportions and percentages and quantitative data were summarized in means and standard deviation. The association of different factors with adherence was analyzed by applying chi square $(\chi 2)$ test, using trial version of SPSS (Statistical Package for Social Sciences). A $p$-value of less than 0.05 was considered to be statistically significant for all analyses.

\section{Results}

The present study was conducted to know the level on non-adherence to anti-hypertensive medications among individuals prescribed treatment of hypertension. Standard Brief Medication Questionnaire I (BMQ I) was used to know drug adherence. Among total of 150 participants $44 \%$ were males and $56 \%$ were females. $30 \%$ of study subjects belonged to the age group of $40-50$ years, $24.7 \%, 60-70$ years, $19.3 \%, 50-60$ years and $17.3 \%$, $30-40$ years age group. Only $8.7 \%$ of the study subjects were $>70$ years age group. (Table 1 )

The magnitude of non-adherence to anti-hypertensive drugs were $35.3 \%$ i.e. 53 subjects and $64.7 \%$ subjects were adherent to anti-hypertensive drugs i.e. 97 subjects. Among non-adherent subjects $54.7 \%$ subjects were females and $45.3 \%$ subjects were males. Among males non-adherence rate was $36 \%$ while in females the rate of non-adherence was $34 \%$. The sex wise difference regarding the adherence pattern was not statistically significant. (Table 2)

(Table 3 ) showed that sex, number of anti-hypertensive drugs prescribed and satisfaction regarding control of hypertension were not significantly associated with adherence to anti-hypertensive drugs, whereas side effects of anti-hypertensive drugs was significant risk factor for non-adherence to anti-hypertensive drugs.

We found that the common reasons for non-adherence to anti-hypertensive medication among study subjects were unwanted side effects i.e. $64.2 \%$ followed by worry about long term side effects, hard to pay for this drug, hard to get my refill on time, hard to remember all the doses and drug causes other concerns or problems i.e. $62.3 \%, 50.9 \%$, 49\%, 45.3\% \& 37.7\% respectively. (Table 4)

\section{Discussion}

In our study we found that $35.3 \%$ of the individuals who were prescribed anti-hypertensive medication were non adherent to the medications. Adherence to long-term therapy for hypertension is an important tool to enhance the effectiveness of pharmacotherapy. The present study was conducted using standard Brief Medication Questionnaire I (BMQ I) to know drug adherence among hypertensive patients. Mantovani et al (14) also found out that that among 146 hypertensive patients $41.0 \%$ was non-adherent or partially adherent to treatment. 
Whereas some other studies like Roy etal(15) and Berisa et al(16) found non adherence rate of $71.4 \%$ and $69.6 \%$ respectively, much higher than reported in our study. In patients with hypertension, despite the availability of effective therapy, hypertension remains poorly controlled in the developed and developing countries. Patient non adherence with prescribed treatments might be central reason for the failure to control hypertension in those receiving therapy. In our study we could not found any significant association in gender and adherence this was in line with studies conducted by Gupta etal(17) and Sahoo etal(18), whereas study conducted by Kazaure et al(19) in Nigeria and Balasubramanian et al(20) in Kerala found significant association between gender and adherence.

In this study we found no statistically significant association between adherence and number of antihypertensive drugs prescribed, this is corroborated with study conducted by Gupta etal and Mekonnenetal(21) Whereas study conducted by Hashmi et al(22) found an inverse relationship between adherence and number of pills prescribed. Patients on monotherapy had a mean adherence of $79 \%$ compared to $60 \%$ for those on three drugs or more.

In this study, most common reason (64.2\%) for nonadherence to anti-hypertensive medication among nonadherent study subjects were unwanted side effects, whereas in other studies conducted by Roy etal(15) and Berisa etal(16) most common reason for non-adherence to drugs were complicated drug regimen $(74.1 \%)$ and forget to take medications $(47.1 \%)$ respectively. Nearly half of the patients (45.3\%) have agreed that it was somewhat hard to remember all the medications, which was consistent with a previous study (15). Half (50.9\%) of the subjects have indicated that it was somewhat hard to pay for their medications; in contrast Roy etal(15) found this reason to non-adherence only in $13.5 \%$ subjects, but Sahoo etal found non-affordability $(66.3 \%)$ major reason for non-adherence. $49 \%$ reported that they had difficulty to get their refill in time, however this was in contrast with a previous study they found this reason to non-adherence only in $20 \%$ subjects.(15)

This study showed that there was statistically significant difference in the satisfaction regarding the working of anti-hypertensive drugs to control blood pressure in adherent subjects as compared to non-adherent group. This study also showed that there was statistically significant difference in the perception of problems regarding the use of anti-hypertensive drugs and adherence. In our study we found that there is statistically significant difference in adherence and the perception of study subjects about the role of anti-hypertensive medication prescribed.

So, most of the factors related to non-adherence can be well addressed by proper briefing about the medications by treating physicians or attending health care workers.

\section{Conclusion}

Prevalence of non-adherence to anti-hypertensive drugs was quite high, most common reason for non-adherence to anti-hypertensive medication was unwanted side effects and worry about long term side effects. Other important reasons for non-adherence were hard to pay for this drug, hard to get my refill on time, hard to remember all the doses. Non adherent subjects were less aware about role and working of the anti-hypertensive medications, also they were facing more problems regarding the use of medications.

\section{Recommendation}

Physicians should counsel every hypertensive patient regarding side effects of anti-hypertensive drugs prescribed and make him/her aware about the mechanism of action of the drugs also. They should also be telling the patients when to come back in case of the side effects persist or are troublesome. Moreover, to reduce out of pocket expenditure from anti-hypertensive drugs government should cover all the population under some health insurance schemes. Doctors should be encouraged to inform and educate each and every hypertensive patient regarding working of antihypertensive drug prescribed.

\section{Limitation of the study}

Hospital-based study, small sample cannot be generalized.

\section{References}

1. Magnusson RS. Non-communicable diseases and global health governance: enhancing global processes to improve health development. Globalization and Health 2007; 3: 2.

2. World Health Statistics 2017: monitoring health for the SDGs, Sustainable Development Goals. Geneva, World Health Organization, 2017. Available on https://www.who.int/gho/publications/world health statistics/2017/EN WHS2017 TOC.pdf?ua=1 (Accessed on 15/10/2019)

3. Non-communicable Diseases Progress Monitor, 2017. Geneva: World Health Organization; 2017. Available on https://apps.who.int/iris/bitstream/handle/10665/258940/9789241513029 -eng.pdf;jsessionid=3A705CEE93CBCA1D2AEC3472A8CB02B0?sequence=1 (Accessed on 15/10/2019)

4. Mills KT, Bundy JD, Kelly TN, Reed JE, Kearney PM, Reynolds K, et al. Global Disparities of Hypertension Prevalence and Control: A Systematic Analysis of Population-based Studies from 90 Countries. Circulation 2016; 134(6): 44150.

5. Anchala R, Kannuri NK, Pant $\mathrm{H}$, Khan $\mathrm{H}$, Franco $\mathrm{OH}$, Di Angelantonio $\mathrm{E}$, et al. Hypertension in India: a systematic review and meta-analysis of prevalence, awareness, and control of hypertension. J Hypertens. 2014; 32:1170-7.

6. Strasser T. (1972). WHO Chronicle, 26: 451.

7. Haynes RB. Determinants of compliance: The disease and the mechanics of treatment. Baltimore MD, Johns Hopkins University Press, 1979.

8. Rand CS. Measuring adherence with therapy for chronic diseases: implications for the treatment of heterozygous familial hypercholesterolemia. Am J Cardiol 1993;72(10):68D-74D.

9. Sackett DL, Haynes RB, Gibson ES, Taylor DW, Roberts RS, Johnson AL. Patient compliance with antihypertensive regimens. Patient Couns Health Educ 1978;1(1):18-21.

10. Leupkar RV. Patient adherence: A "risk factor" for cardiovascular disease. The Framington Study. JAMA1971; 215:1617-25.

11. Moreira L, Fernandes $P$, Monte S, Martins A. Medication Compliance in Patients with Chronic Kidney Disease. J Nephrol 2008;21(3):354-62.

12. Osterberg L, Blaschke T. Adherence to medication. N Engl J Med 2005;353(5):487-497.

13. Tarn DM, Heritage J, Paterniti DA, Hays RD, Kravitz RL, Wenger NS. Physician communication when prescribing new medications. Arch Intern Med 2006;166(17):1855-62. 
INDIAN JOURNAL OF COMMUNITY HEALTH / VOL 32 / ISSUE NO 01 / JAN - MAR 2020

14. Mantovani MDF, Mattei AT, Arthur JP, Ulbrich EM, Moreira RC. The use of the brief medication questionnaire in medication accession of hypertensives. J Nurs 2015; 9(1):84-90.

15. Roy NT, Sajith M, Bansode MP. Assessment of Factors Associated with Low Adherence to Pharmacotherapy in Elderly Patients. J Young Pharm. 2017;9(2):272-6.

16. Berisa HD, Dedefo MG. Non-adherence related factors to antihypertensive medications among hypertensive patients on follow up at nedjo general hospital in West Ethiopia. Open Pub Health J 2018; 11: 62-71.

17. Gupta MC, Bhattacharjee A, Singh H. Evaluation of medication adherence patterns amongst anti-hypertensive drug users in a tertiary care hospital in north India. Int J Basic Clin Pharmacol 2016; 5:2261-6.

18. Sahoo SK, Preeti PS, Biswas D. Adherence to Anti-Hypertensive Drugs: A Clinic Based Study among Geriatric Hypertensive Patients in Rural, India. Nat J Community Med 2018; 9(4): 250- 54
[Non-Adherence to] | Shalini et al

19. Kazaure AZ, Abubakar AA, Ibrahim MS, Gidado S, Sabitu K, Nguku P. Factors for nonadherence to antihypertensive drugs among Federal Civil Servants attending health facilities - Abuja, FCT. Sub-Saharan African Journal of Medicine Jan-March 2017;4(1):20-25.

20. Balasubramanian A, Nair SS, Rakesh PS, Leelamoni K. Adherence to treatment among hypertensives of rural Kerala, India. J Family Med Prim Care 2018; 7:64-9.

21. Mekonnen HS, Gebrie $\mathrm{MH}$, Eyasu $\mathrm{KH}$, Gelagay AA. Drug adherence fo antihypertensive medications and its determinants among adult hypertensive patients attending in chronic clinics of referral hospitals in Northwest Ethiopia. BMC PharmacolToxicol 2017; 18: 27.

22. Hashmi SK, Afridi MB, Abbas K, Sajwani RA, Saleheen D, Frossard PM, et al. Factors associated with adherence to anti-hypertensive treatment in Pakistan. PLoS One. 2007;2: e280.

\section{Tables}

TABLE 1 DISTRIBUTION OF STUDY SUBJECTS ACCORDING TO AGE AND SEX

\begin{tabular}{|l|l|l|l|}
\hline Age Group (Years) & Male (\%) & Female (\%) & Total (\%) \\
\hline $30-40$ & $9(13.6)$ & $17(20.2)$ & $26(17.3)$ \\
\hline $40-50$ & $21(31.8)$ & $24(28.6)$ & $45(30)$ \\
\hline $50-60$ & $12(18.2)$ & $17(20.2)$ & $29(19.3)$ \\
\hline $60-70$ & $18(27.3)$ & $19(22.6)$ & $37(24.7)$ \\
\hline$>70$ & $6(9.1)$ & $7(8.3)$ & $13(8.7)$ \\
\hline Total & $66(100)$ & $84(100)$ & $150(100)$ \\
\hline Mean \pm SD & $54.15 \pm 13.50$ & $52.17 \pm 13.12$ & \\
\hline
\end{tabular}

TABLE 2 DISTRIBUTION OF SUBJECTS ACCORDING TO AGE \& ADHERENCE TO ANTI HYPERTENSIVE DRUGS

\begin{tabular}{|c|c|c|c|}
\hline \multirow[t]{2}{*}{ Age } & \multicolumn{2}{|l|}{ Drug Adherence } & \multirow[t]{2}{*}{ Total } \\
\hline & Non adherent (\%) & Adherent (\%) & \\
\hline $30-40$ & $13(24.53)$ & $13(13.40)$ & $26(17.3)$ \\
\hline $40-50$ & $13(24.53)$ & $32(32.99)$ & $45(30)$ \\
\hline $50-60$ & $13(24.53)$ & $16(16.49)$ & $29(19.33)$ \\
\hline $60-70$ & $11(20.75)$ & $26(26.80)$ & $37(24.67)$ \\
\hline$>70$ & $3(5.66)$ & $10(10.31)$ & $13(8.67)$ \\
\hline Total & $53(100)$ & $97(100)$ & $150(100)$ \\
\hline
\end{tabular}

TABLE 3 ADHERENCE TO ANTI HYPERTENSIVE DRUGS AND ASSOCIATION WITH SEX, NUMBER OF ANTI HYPERTENSIVE DRUGS PRESCRIBED

\begin{tabular}{|c|c|c|c|c|c|c|}
\hline \multicolumn{2}{|l|}{ Variables } & \multicolumn{2}{|l|}{ Drug Adherence } & \multirow{4}{*}{$\begin{array}{l}\text { Total } \\
66(44) \\
84(56)\end{array}$} & \multirow{4}{*}{$\begin{array}{l}\text { Chi-square } \\
\text { value } \\
0.08\end{array}$} & \multirow{4}{*}{$\begin{array}{l}p \text { value } \\
>0.05\end{array}$} \\
\hline & & \multirow{3}{*}{$\begin{array}{l}\text { Non adherent (\%) } \\
24(45.28) \\
29(54.72)\end{array}$} & \multirow{2}{*}{$\begin{array}{l}\text { Adherent (\%) } \\
42(43.3)\end{array}$} & & & \\
\hline Sex & Male & & & & & \\
\hline & Female & & $55(56.7)$ & & & \\
\hline \multirow{2}{*}{$\begin{array}{l}\text { Number of drugs } \\
\text { prescribed }\end{array}$} & One & $38(71.7)$ & $79(81.4)$ & $117(78)$ & \multirow[t]{2}{*}{2.62} & \multirow[t]{2}{*}{$>0.05$} \\
\hline & More than one & $15(28.3)$ & $18(18.6)$ & $33(22)$ & & \\
\hline \multirow{2}{*}{$\begin{array}{l}\text { Satisfaction regarding } \\
\text { control of Hypertension }\end{array}$} & Satisfied & $48(90.57)$ & $92(94.85)$ & $140(93.33)$ & \multirow[t]{2}{*}{1.36} & \multirow[t]{2}{*}{$>0.05$} \\
\hline & $\begin{array}{l}\text { Not satisfied/ Do } \\
\text { Not Know }\end{array}$ & $5(9.43)$ & $5(5.15)$ & $10(6.67)$ & & \\
\hline \multirow{2}{*}{$\begin{array}{l}\text { Side effects of anti- } \\
\text { hypertensive drugs }\end{array}$} & Yes & $39(73.58)$ & $37(38.14)$ & $67(44.67)$ & \multirow[t]{2}{*}{25.47} & \multirow[t]{2}{*}{$<0.001$} \\
\hline & No/ Do Not Know & $14(26.42)$ & $60(61.86)$ & $74(53.33)$ & & \\
\hline \multicolumn{2}{|l|}{ Total } & $53(100.0)$ & $97(100.0)$ & $150(100)$ & & \\
\hline
\end{tabular}

TABLE 4 REASONS FOR NON-ADHERENCE TO ANTI-HYPERTENSIVE MEDICATION AMONG NON-ADHERENT STUDY SUBJECTS ( $N=53$ ) AS PER BMQ1*

\section{Reasons t}

It is hard to remember all the doses

It is hard to pay for this drug

It is hard to get my refill on time

I still get unwanted side effects from this drug

I worry about the long-term effects of this drug

This drug causes other concerns or problems

Brief Medication Questionnaire I*, Subjects had multiple responses ${ }^{\dagger}$
Number (\%)

24 (45.3)

27 (50.9)

26 (49)

34 (64.2)

$33(62.3)$

20 (37.7) 